\title{
Correlates of psychological intimate partner violence with HIV care outcomes on patients in HIV care
}

\author{
R. J. Fredericksen ${ }^{1 *}$ D, R. M. Nance ${ }^{1}$, B. M. Whitney ${ }^{1}$, B. N. Harding ${ }^{1}$, E. Fitzsimmons ${ }^{1}$, C. Del Rio ${ }^{2}$, J. Eron ${ }^{3}$, \\ D. J. Feaster ${ }^{4}$, A. S. Kalokhe ${ }^{5}$, W. C. Mathews ${ }^{6}$, K. H. Mayer ${ }^{7}$, L. R. Metsch ${ }^{8}$, M. J. Mugavero ${ }^{9}$, J. Potter ${ }^{10}$, \\ C. O'Cleirigh ${ }^{11}$, S. Napravnik ${ }^{12}$, B. Rodriguez ${ }^{13}$, S. Ruderman ${ }^{1}$, Delaney JAC ${ }^{14}$ and H. M. Crane ${ }^{1}$
}

\begin{abstract}
Background: Among people living with HIV (PLWH), physical intimate partner violence (IPV) is associated with poor virologic, psychiatric, and behavioral outcomes. We examined non-physical, psychological intimate partner violence (psy-IPV) and HIV care outcomes using data from two U.S. consortia.

Methods: We conducted multivariable analyses with robust standard errors to compare patients indicating/not indicating psy-IPV.

Results: Among PLWH ( $n=5950), 9.5 \%$ indicated psy-IPV; these individuals were younger $(-3 ; 95 \% \mathrm{Cl}[-2,-4]$, $p$ value $<0.001)$, less likely to be on antiretroviral treatment (ART) $(0.73[0.55,0.97], p=0.03)$, less adherent to ART ($4.2[-5.9,-2.4], p<0.001)$, had higher odds of detectable viral load $(1.43[1.15,1.78], p=0.001)$ and depression $(2.63$ $[2.18,3.18], p<0.001)$, and greater use of methamphetamines/crystal $[2.98(2.30,3.87), p<0.001]$, cocaine/crack [1.57 $(1.24,1.99), p<0.001]$, illicit opioids [1.56 (1.13,2.16), $p=0.007]$, and marijuana [1.40 (1.15,1.70), $p<0.001]$.
\end{abstract}

Conclusion: Psychological IPV, even in the absence of physical or sexual IPV, appears to be associated with HIV care outcomes and should be included in IPV measures integrated into routine HIV care.

Keywords: Psychological violence, HIV care, Patient reported outcomes

\section{Background}

Intimate partner violence (IPV) is defined as physical, sexual, and/or psychological violence by a current or former intimate partner [1]. Psychological IPV (psy-IPV) is defined as the use of verbal and non-verbal communication with the intent to harm another person mentally or emotionally, and/or to exert control over another person [1]. IPV is known to disproportionately affect women, and men who have sex with men (MSM); lifetime global prevalence of physical or sexual IPV against

\footnotetext{
* Correspondence: rfrederi@uw.edu

${ }^{1}$ Department of Medicine, University of Washington, Seattle, Washington, USA

Full list of author information is available at the end of the article
}

ever-partnered women is estimated at $27 \%$ with a past 12 -month prevalence of $13 \%$ ( 25 and $6 \%$ respectively for North America) [2]; in the U.S., men who have sex with men (MSM) are estimated to have physical and sexual IPV rates similar to heterosexual women [3]. Psy-IPV estimates suggest a rate of $\sim 47 \%[4,5]$. Studies among people living with HIV (PLWH), among women and MSM, show high and wide ranging lifetime physical IPV (26-62\%/15-39\%), sexual IPV, (22-44\%/8-33\%), and psy-IPV (55\%/22-73\%) [6]. Among substance-using PLWH, lifetime rates of all types of IPV have been found to be very high: $56 \%$ among cocaine/crack-using PLWH in the southern U.S., with the highest rates among women and gay men (68 and 71\%) [7]. 
To date, there has been a lack of robust systematicallycollected data on IPV rates across large populations of PLWH. Living with HIV has been associated with both psychological and physical IPV [8], and any IPV among PLWH has been associated with poorer antiretroviral treatment (ART) adherence, more clinically relevant interruptions in care [7, 9-11], and increased HIV-related hospitalizations [11]. In addition, in both PLWH and those without HIV, any IPV has been associated with psychiatric conditions, such as depression [6, 12-15] and post-traumatic stress disorder (PTSD) $[6,16]$ and adverse health behaviors, including substance abuse $[6$, 12, 17-20] and high-risk sexual behavior $[4,6,21,22]$. There appears to be a link between IPV and immune defenses. Among HIV-negative women at high risk for contracting HIV, both lifetime and past-year violence of any type was associated with increased CD4+ activation [23]; among PLWH, physical IPV has been shown to have a negative impact on virologic outcomes [24] and CD4+/CD8+ T-cell decay [25].

Psychological IPV is less well-studied. However, it appears to be more common than physical or sexual IPV [26-28], and, in a longitudinal study of women, more likely to continue in the absence of physical or sexual IPV [29]. Stress induced by psy-IPV has an impact similar to physical IPV on immune functioning $[23,24]$ and a negative impact on an array of health behaviors and outcomes $[16,30]$. One study suggested that psy-IPV has been associated with a detectable viral load, CD4 < 200, and high no-show rate for HIV care visits [24]. However, this study was limited by a small sample size at a single site [24]. A longitudinal study of young ARTnaïve women with HIV in South Africa found psy-IPV in the form of emotional abuse was associated with a faster decline in markers of cellular immunity even when controlling for exposure to physical or sexual IPV [25]. In HIV-uninfected populations, psy-IPV has been associated with adverse mental health and behavioral outcomes including depression severity [31], post-traumatic stress symptom severity [31], substance use [32], and sexual risk behavior [4], the latter even when controlling for physical and sexual violence [16]. Outcomes and factors such as substance use, HIV, and violence, have been described as a syndemic [33]; these, along with mental health impacts, appear inter-related and synergistic [33]. For example, avoidance behavior associated with PTSD has been found to mediate the relationship between psyIPV and substance use, depression severity, and sexual risk behavior [16, 31].

Most studies of psy-IPV have been limited in scope in terms of both population and outcomes, with most focusing exclusively on women $[16,23,25,30]$. We sought to better understand the correlates and impact of psyIPV in a large geographic, clinical, and gender-diverse sample of PLWH on HIV care continuum outcomes and health behaviors. Building on prior work among women in the general population or small studies of PLWH [23, 25], we hypothesized that psy-IPV will inhibit viral suppression/CD4. In addition, as noted in populations having experienced physical IPV, we hypothesized psy-IPV will worsen ART adherence among PLWH, $[7,9,10]$ increase depressive symptoms [12-14], and increase substance use [12, 17-20].

\section{Methods \\ Study population}

This cross-sectional study included PLWH from two large collaborations in the U.S. including Puerto Rico to ensure demographic, geographic, and clinical diversity, with PLWH from geographically dispersed clinical care settings to enhance generalizability and study settings focused on substance using PLWH to ensure inclusion of vulnerable populations. Centers for AIDS Research Network of Integrated Clinical Sites (CNICS) (https://www. uab.edu/cnics/) is a cohort study of PLWH in clinical care at eight sites across the US from 1995 to present [34]. Seek, Test, Treat, Retain (STTR) is a consortium initiated by the National Institute on Drug Abuse [35, 36] to address research questions related to HIV care continuum outcomes among vulnerable particularly substance using populations.

\section{Study subjects}

From CNICS, we included PLWH representing six CNICS sites: the 1917 Clinic at University of AlabamaBirmingham; Case Western Reserve University in Cleveland, $\mathrm{OH}$; Fenway Community Health-Boston, MA; Owen Clinic at University of California at San Diego; University of North Carolina; and Madison Clinic at Harborview Medical Center/University of WashingtonSeattle. IPV data collection from these patients began in 2016. From the STTR study consortium, we included PLWH from two studies: Proyecto PACTo (Proveyendo Acceso a Cuidado y Tratamiento) [37], and Project RETAIN [38].

Proyecto PACTo is a clinical trial which evaluated effectiveness of the "Enhanced HIV Care Access and Retention Intervention" in achieving HIV virologic suppression among substance using PLWH in Puerto Rico that ran from 2013 to 2014. Project RETAIN is a clinical trial done to evaluate the efficacy of an integrated "Retention Clinic" in achieving virologic suppression among cocaine/crack-using PLWH in Florida and Georgia that ran from 2013 to 2015.

For both the STTR (PACTO/RETAIN) and CNICS groups, our analyses included PLWH who were 18 years of age or older and completed a self-administered patient-reported outcome (PRO) measure querying IPV. 
For PACTO/RETAIN, we included PLWH who answered IPV questions at their baseline visit. For CNICS, we included PLWH that had been administered the IPV measure in their most recent PRO assessment at the beginning of their routine care visit. Table 1 shows full inclusion and exclusion criteria across consortia and networks.

\section{Data sources}

Both CNICS and STTR have data repositories that harmonize and integrate demographic, clinical, laboratory, and other data such as patient-reported measures including IPV [36, 39].

\section{Psychological intimate partner violence measures}

CNICS utilizes a brief validated measure, the IPV-4 [40], that is inclusive of physical IPV, sexual IPV, and two forms of psy-IPV (see Table 2): controlling behavior by an intimate partner and fearfulness of a partner in the past year. The IPV-4, initiated in 2016, is administered to PLWH within CNICS clinics on-site prior to their clinic visit as part of routine care. The PACTO and RETAIN studies used the second two items of a lifetime IPV measure known as STaT [an acronym for 'slapped, threatened, and throw (things)'], as well as an item querying controlling behavior that was used in development of the STaT measure [41]; these items were adapted to reflect a 6 month recall period (Table 2). Data from items regarding controlling behavior were harmonizable across CNICS and PACTO/RETAIN (in Table 2, CNICS item 1 harmonizes with PACTO/RETAIN item
Table 2 Psychological intimate partner violence measures

$$
\text { CNICS: }
$$

1. In the PAST YEAR, did a current or former partner... Make you feel cut off from others, trapped, or controlled in a way you did not like?

2. In the PAST YEAR, did a current or former partner... Make you feel afraid that they might try to hurt you in some way?

PACTO and RETAIN:

1. In the past 6 months, have you ever been in a relationship where a sexual partner threatened you with violence?

2. In the past 6 months, have you ever been in a relationship where a sexual partner threw, broke, or punched things?

3. In the past 6 months, have you ever been in a relationship where you felt controlled by a sexual partner?

Response options: Yes, No

3), as were data regarding threatening behavior (in Table 2, CNICS item 2 harmonizes with PACTO/RETAIN items 1 and 2); these two areas comprise our dimensions of psy-IPV. Psy-IPV was considered reported if a person answered "yes" to any of these items.

\section{Safety protocols}

All participants were informed that responses to study measures are kept confidential within their respective sites and that data used for research purposes is deidentified. In CNICS, patients are informed, prior to answering questions, that their providers will see their responses. Patients in all studies were given the option of not answering any questions. PLWH in CNICS indicating any type of violence in the IPV-4 prompt a pager alert for an on-site social worker to check-in with the patient, same-day, on-site during their clinic visit, at

Table 1 Psy-IPV study population: inclusion/exclusion criteria, data collection dates, and regions

\begin{tabular}{|c|c|c|c|c|}
\hline Consortium & Inclusion criteria & Exclusion criteria & $\begin{array}{l}\text { Data } \\
\text { collection } \\
\text { dates }\end{array}$ & Regions \\
\hline \multirow[t]{4}{*}{ CNICS } & $\geq 18$ & \multirow{4}{*}{$\begin{array}{l}\text { Unable or unwilling to complete } \\
\text { questionnaire }\end{array}$} & \multirow[t]{4}{*}{ 2016-2018 } & \multirow{4}{*}{$\begin{array}{l}\mathrm{AL}, \mathrm{CA} \\
\mathrm{MA}, \mathrm{NC} \\
\mathrm{OH}, \mathrm{WA}\end{array}$} \\
\hline & PLWH & & & \\
\hline & In routine HIV care & & & \\
\hline & English or Spanish-speaking & & & \\
\hline \multirow{4}{*}{$\begin{array}{l}\text { PACTO } \\
\text { (STTR) }\end{array}$} & $\geq 18$ & \multirow{4}{*}{$\begin{array}{l}\text { Unable to consent due to cognitive or } \\
\text { developmental impairment }\end{array}$} & \multirow[t]{4}{*}{ 2013-2014 } & \multirow{4}{*}{$\begin{array}{l}\text { Puerto } \\
\text { Rico }\end{array}$} \\
\hline & PLWH & & & \\
\hline & Able to communicate in English & & & \\
\hline & $\begin{array}{l}\text { Report any drug (excluding nicotine) and/or heavy alcohol use } \\
\text { within the past } 12 \text { months }\end{array}$ & & & \\
\hline \multirow{4}{*}{$\begin{array}{l}\text { RETAIN } \\
\text { (STTR) }\end{array}$} & $\geq 18$ & \multirow{3}{*}{$\begin{array}{l}\text { Unable to consent due to cognitive or } \\
\text { developmental impairment }\end{array}$} & \multirow[t]{4}{*}{ 2013-2015 } & \multirow[t]{4}{*}{$F L, G A$} \\
\hline & PLWH & & & \\
\hline & Cocaine/crack use in past 3 months & & & \\
\hline & $\begin{array}{l}\text { AIDS-defining illness OR CD } 4<350 \text { AND a viral load }>1000 \text { copies/ } \\
\text { mL in the medical record in the past } 3 \text { months, OR Have a CD4 } \\
\text { count }<350 \text { cells/uL AND a viral load }>200 \text { copies } / \mathrm{mL} \text { as obtained } \\
\text { via baseline blood draw, OR Clinical profile indicative of a } \\
\text { persistently detectable HIV viral load ( }>200 \text { copies } / \mathrm{mL} \text { ) }\end{array}$ & $\begin{array}{l}\text { Currently receiving patient navigator } \\
\text { services for HIV care or substance use } \\
\text { treatment }\end{array}$ & & \\
\hline
\end{tabular}


which point they are evaluated and provided with resources if needed. For the PACTO and RETAIN studies, indication of IPV prompted an assessment in real time with the patient by a licensed psychologist who was part of the study team.

\section{Outcomes}

We examined the association between psy-IPV and the following risk behaviors and symptoms: depressive symptoms, ART adherence, current use of methamphetamine/crystal, cocaine/crack, illicit opioids, marijuana, and alcohol, as well as current binge alcohol use. Depressive symptoms was defined as a score of $\geq 10$ on the PHQ-9 $[42,43]$ in CNICS, and a score of $\geq 16$ on the Center for Epidemiological Studies-Depression (CES-D-20) [44] measure in PACTO and RETAIN. Adherence to ART was measured as a percentage of HIV medication taken over the past 30 days [45]. Current alcohol use was defined as a score of $\geq 1$ as measured by the AUDIT-C [46] and current binge drinking was defined as having had 5 or more drinks on one occasion using the AUDIT-C. Drug use was identified using the ASSIST [47] which includes methamphetamines, illicit opioids, cocaine/crack, sedatives, stimulants, hallucinogens, inhalants, and marijuana. We examined associations between psy-IPV and clinical outcomes including HIV care cascade steps, specifically ART use, detectable viral load, and CD4 count, as well as self-reported ART adherence.

\section{Statistical analysis}

We performed statistical analysis using STATA version 14.2. We used logistic regression for analyses with binary variables and linear regression for analyses with continuous variables, to compare those who did and did not indicate psy-IPV. Observations were weighted by inverse probability of treatment weights (IPTW) to reduce the ratio of adjustment factors to outcomes in models; IPTW using propensity scores is a good alternative to control for confounding when there are seven or fewer events per confounder [48]. We generated propensity scores using logistic regression based on the model by Hernan et al. (2000) [49]. IPTWs were calculated using two different propensity score models to estimate the propensity of indicating psy-IPV: (1) Propensity of indicating psy-IPV was estimated adjusting for a limited set of covariates including age, site, and race/ethnicity; (2) Propensity of indicating psy-IPV was estimated by adjusting for a larger set of covariates including age, site, race/ethnicity, current substance use (methamphetamine, cocaine/crack, illicit opioids, marijuana, alcohol and binge alcohol use) and depressive symptoms. Age was modeled linearly. Propensity score density plots were created for both scores to assess adequacy of overlap between participants that reported psy-IPV and those that did not report psy-IPV. We performed sensitivity analyses in CNICS with propensity scores that also adjusted for physical IPV. We examined demographic characteristics among those with and without psy-IPV including age, sex, race/ethnicity, and sexual orientation. We examined psy-IPV and risk behaviors and symptoms as well as clinical characteristics including HIV care cascade steps. These associations were assessed using the limited IPTW, and associations except depressive symptoms and substance use were also assessed using the more complex IPTW. When age was compared between those with and without psy-IPV, the model was not weighted and simply adjusted for study and race since age was in both IPTWs. We examined the association of psy-IPV and HIV care cascade variables exclusively in the CNICS cohort, due to smaller sizes of the other studies. We note that due to discordant recall periods between the IPV measures administered by study sites, we did not perform formal mediation analyses.

A list of all statistical models that were run can be found in Supplemental Table 1.

\section{Results \\ Study population}

A total of 5950 PLWH were included in this study, with 564 (10\%) indicating recent psy- IPV; CNICS contributed the largest number of participants (5195), followed by PACTO (408), and RETAIN (347) (Table 3). Of the 5950 participants, $18 \%$ were female sex at birth, and the mean age was 47 years. One percent of participants were transgender. Race and ethnicity varied across studies, with CNICS having 45\% white, PACTO having 99\% Hispanic, and RETAIN having $82 \%$ black participants. Depressive symptoms (25\%) and substance use (up to 62\%) were commonly reported. In CNICS, which assessed physical/sexual and psy-IPV, 50\% of those indicating psy-IPV did not report physical/sexual IPV. PACTO/RETAIN did not have data on physical or sexual IPV within a harmonizable time window (asked lifetime only), hence, psy-IPV independent of physical/sexual IPV could not be assessed for those sites.

\section{Associations with psychological IPV}

Propensity score density plots (Supplemental Figs. 1 and 2) showed good overlap between participants reporting psy-IPV and those not reporting psy-IPV, confirming that IPTW is an appropriate method to control for confounding (Table 4; see Supplemental Tables 2, 3, and 4 for breakdowns by study site). Those reporting psy-IPV were on average 3 years younger (95\% CI $[2,4], p$-value $<0.001)$. In models using the limited IPTW, psy-IPV was significantly associated with HIV outcomes including lower odds of ART use (0.73 [0.55,0.97], $p=0.03)$, 
Table 3 Demographic and clinical characteristics of PLWH by study

\begin{tabular}{|c|c|c|c|c|}
\hline Study & CNICS & РАCTO $^{a}$ & RETAIN $^{\mathrm{a}}$ & Total \\
\hline $\mathbf{N}$ & 5195 & 408 & 347 & 5950 \\
\hline Any psy-IPV & $457(9 \%)$ & $71(17 \%)$ & $36(10 \%)$ & $564(9 \%)$ \\
\hline Felt controlled, but not threatened & $194(4 \%)$ & $13(3 \%)$ & $2(0.6 \%)$ & $209(4 \%)$ \\
\hline Felt threatened, but not controlled & $38(0.7 \%)$ & $18(4 \%)$ & $7(2 \%)$ & $63(1 \%)$ \\
\hline Felt both controlled and threatened & $225(4 \%)$ & $40(10 \%)$ & $27(8 \%)$ & $292(5 \%)$ \\
\hline Female $^{b}$ & $855(16 \%)$ & $94(23 \%)$ & $124(36 \%)$ & $1073(18 \%)$ \\
\hline Age (mean, SD) & $47(12)$ & $46(9)$ & $46(9)$ & $47(11)$ \\
\hline \multicolumn{5}{|l|}{ Race/ethnicity } \\
\hline White & $2320(45 \%)$ & $1(0 \%)$ & $15(4 \%)$ & $2336(39 \%)$ \\
\hline Black & $1811(35 \%)$ & $0(0 \%)$ & $286(82 \%)$ & $2097(35 \%)$ \\
\hline Hispanic & $779(15 \%)$ & 405 (99\%) & $32(9 \%)$ & $1216(20 \%)$ \\
\hline Other/Unknown & $285(5 \%)$ & $2(0 \%)$ & $14(4 \%)$ & $301(5 \%)$ \\
\hline Heterosexual & $1434(28 \%)$ & $348(85 \%)$ & $173(50 \%)$ & 1955 (33\%) \\
\hline Men who have sex with men & $3401(66 \%)$ & $41(10 \%)$ & 45 (19\%) & $3487(60 \%)$ \\
\hline $\mathrm{VL} \geq 400$ & 466 (9\%) & 192 (47\%) & $326(94 \%)$ & $984(17 \%)$ \\
\hline CD4 (mean, SD) & $668(331)$ & $540(346)$ & $181(150)$ & $631(344)$ \\
\hline Depression & $926(18 \%)$ & $325(80 \%)$ & $264(76 \%)$ & $1515(25 \%)$ \\
\hline ART use & $4827(93 \%)$ & $297(73 \%)$ & $191(55 \%)$ & $5315(89 \%)$ \\
\hline $\begin{array}{l}\text { ART adherence } \\
\text { (mean \%, SD) }\end{array}$ & $94(14)$ & $95(16)$ & $90(21)$ & $94(14)$ \\
\hline \multicolumn{5}{|l|}{ Substance Use } \\
\hline Methamphetamine/crystal & $446(9 \%)$ & $6(1 \%)$ & $3(1 \%)$ & $455(8 \%)$ \\
\hline Cocaine/crack & $295(6 \%)$ & $230(56 \%)$ & $244(70 \%)$ & 769 (13\%) \\
\hline Illicit opioid & $107(2 \%)$ & $186(46 \%)$ & $29(8 \%)$ & $322(5 \%)$ \\
\hline Marijuana & $1514(29 \%)$ & $106(26 \%)$ & 118 (34\%) & $1738(29 \%)$ \\
\hline Alcohol & $3319(64 \%)$ & $162(40 \%)$ & $224(65 \%)$ & $3705(62 \%)$ \\
\hline Binge alcohol & 1677 (32\%) & 109 (27\%) & $158(46 \%)$ & $1944(33 \%)$ \\
\hline
\end{tabular}

PACTO and RETAIN were both STTR studies

${ }^{\mathrm{b}}$ Birth sex

'Adherence defined as $\%$ of medication taken in past 30 days

Abbreviations: ARTantiretroviral therapy; IPV intimate partner violence; SD standard deviation; VL viral load

lower ART adherence $(-4.2[-5.9,-2.4], p<0.001)$, and higher odds of having a detectable VL $(1.43$ [1.15,1.78], $p=0.001)$. Psy-IPV was also associated with higher odds of depressive symptoms $(2.63[2.18,3.18], p<0.001)$ and greater odds of methamphetamine, cocaine/crack, illicit opioid, and marijuana use, with methamphetamine use having the largest odds ratio (2.98 [2.30,3.87], $p<0.001)$. Female sex at birth, alcohol use, binge alcohol use, sexual orientation, and CD4 count were not significantly associated with psy-IPV.

Using the full IPTW, which additionally adjusted for depressive symptoms and substance use, effect sizes for psy-IPV were uniformly smaller and psy-IPV was no longer associated with most outcomes (e.g. ART use, CD4 count) except for ART adherence (-1.5 [-3.1,-0.2], $p=0.047)$. After including depressive symptoms and substance abuse in the propensity score, female sex was significant for psy-IPV in PACTO and RETAIN (Table 4, Supplement Tables 2, 3 and 4).

In CNICS, $50 \%$ of patients who indicated psy-IPV did not also indicate physical or sexual IPV. Our sensitivity analysis on the effects of psy-IPV adjusting for physical and sexual IPV in CNICS (Table 5) showed that when using a propensity score that includes age, site, race/ethnicity, and physical/sexual IPV, that psy-IPV was associated with having a viral load $\geq 400[1.82(1.20,2.76), p=$ $0.005]$, depressive symptoms [3.21 $(2.42,4.27), p<0.001]$, lower odds of using ART [0.52 $(0.32,0.87), 0.01]$, and higher odds of methamphetamine/crystal, cocaine/crack, and illicit opioid use [2.25 (1.57,3.24), $p<0.001 ; 2.01$ $(1.25,3.22), p=0.004 ; 2.06(1.08,3.95), p=0.03$, respectively]. Additionally, after adjusting for site, race/ethnicity, and physical/sexual IPV, those who indicated psyIPV were on average 1.8 years younger $(-3.1,-0.6), p=$ 
Table 4 Factors associated with psy-IPV. Inverse probability of treatment weights (IPTW) used based on propensity scores

\begin{tabular}{|c|c|c|}
\hline & $\begin{array}{l}\text { IPTW with propensity score including age, site, } \\
\text { race/ethnicity only }\end{array}$ & $\begin{array}{l}\text { IPTW with propensity score including age, site, race/ethnicity, } \\
\text { substance use, depression }\end{array}$ \\
\hline Characteristic & OR for IPV $(95 \% \mathrm{Cl}), p$-value & OR for IPV $(95 \% \mathrm{Cl}), p$-value \\
\hline Female & $1.20(0.95,1.51), 0.1$ & $1.24(0.96,1.60), 0.1$ \\
\hline$V L \geq 400$ & $1.43(1.15,1.78), 0.001$ & $1.21(0.94,1.57), 0.1$ \\
\hline Depression & $2.63(2.18,3.18),<0.001$ & NA \\
\hline ART use & $0.73(0.55,0.97), 0.03$ & $0.86(0.62,1.18), 0.3$ \\
\hline $\begin{array}{l}\text { Methamphetamine/ } \\
\text { crystal use }\end{array}$ & $2.98(2.30,3.87),<0.001$ & NA \\
\hline Cocaine/crack use & $1.57(1.24,1.99),<0.001$ & NA \\
\hline Illicit opioid use & $1.56(1.13,2.16), 0.007$ & NA \\
\hline Marijuana use & $1.40(1.15,1.70), 0.001$ & NA \\
\hline Alcohol use & $1.04(0.86,1.27), 0.7$ & NA \\
\hline Binge alcohol use & $1.18(0.98,1.43), 0.09$ & NA \\
\hline Heterosexual $^{a}$ & $0.87(0.71,1.06), 0.2$ & $0.87(0.69,1.09), 0.2$ \\
\hline Outcome & Coeff for IPV (95\%Cl),p-value & Coeff for IPV $(95 \% \mathrm{Cl}), \mathrm{p}$-value \\
\hline CD4 & $13.1(-20.0,46.3), 0.4$ & $-3.6(-40.5,33.3), 0.8$ \\
\hline ART adherence (VAS) & $-4.2(-5.9,-2.4),<0.001$ & $-1.5(-3.1,-0.2), 0.047$ \\
\hline $\mathrm{Age}^{\mathrm{b}}$ & $-3.2(-4.1,-2.3),<0.001$ & NA \\
\hline
\end{tabular}

Abbreviations: ART antiretroviral therapy; IPV intimate partner violence; VAS visual analog scale; VL viral load

Note: due to missing data, $\mathrm{N}$ for larger propensity score was 5422 with 490 IPV

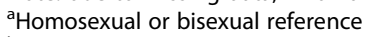

${ }^{\mathrm{b}}$ Not weighted, adjusted for age and race/ethnicity

Table 5 Association of any IPV (psychological) with demographic and clinical characteristics in CNICS. Inverse probability of treatment weights (IPW) used based on propensity scores including physical IPV. Note: due to missing data, N for larger propensity score was 4646 with 379 IPV

IPW with propensity score including age, site, race/ IPW with propensity score including age, site, race/ethnicity, ethnicity, physical/sexual IPV only

\begin{tabular}{|c|c|c|}
\hline Characteristic & OR for IPV $(95 \% \mathrm{Cl}), p$-value & OR for IPV $(95 \% \mathrm{Cl}), \mathrm{p}$-value \\
\hline Female & $0.80(0.54,1.20), 0.3$ & $0.67(0.43,1.05), 0.08$ \\
\hline$V L>=400$ & $1.82(1.20,2.76), 0.005$ & $1.45(0.88,2.40), 0.1$ \\
\hline Depression & $3.21(2.42,4.27),<0.001$ & NA \\
\hline ART use & $0.52(0.32,0.87), 0.01$ & $0.87(0.48,1.56), 0.6$ \\
\hline $\begin{array}{l}\text { Methamphetamine/ } \\
\text { crystal use }\end{array}$ & $2.25(1.57,3.24),<0.001$ & NA \\
\hline Cocaine/crack use & $2.01(1.25,3.22), 0.004$ & NA \\
\hline Opioid use & $2.06(1.08,3.95), 0.03$ & NA \\
\hline Marijuana use & $1.20(0.90,1.60), 0.2$ & NA \\
\hline Alcohol use & $1.29(0.96,1.75), 0.09$ & NA \\
\hline Binge alcohol use & $1.24(0.94,1.64), 0.1$ & NA \\
\hline Heterosexual $^{\mathrm{a}}$ & $0.78(0.56,1.09), 0.1$ & $0.67(0.46,0.98), 0.04$ \\
\hline Outcome & Coeff for IPV $(95 \% \mathrm{Cl})$,p-value & Coeff for IPV (95\%Cl),p-value \\
\hline CD4 & $14.6(-29.4,58.6), 0.5$ & $8.5(-40.5,57.5), 0.7$ \\
\hline $\begin{array}{l}\text { ART adherence } \\
\text { (VAS) }\end{array}$ & $-2.6(-4.6,-0.7), 0.007$ & $-0.5(-2.0,1.0), 0.5$ \\
\hline $\mathrm{Age}^{\mathrm{b}}$ & $-1.8(-3.1,-0.6), 0.005$ & NA \\
\hline
\end{tabular}

Abbreviations: ART-antiretroviral therapy; IPV-intimate partner violence; VAS-visual analog scale; VL-viral load

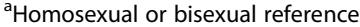

${ }^{\mathrm{b}}$ Not weighted, adjusted for age and race/ethnicity 
0.005 than those who did not. When adding substance use and depressive symptoms to the propensity score analysis, these associations were no longer present.

In analyses that stratified by viral load, psy-IPV was significantly associated with depressive symptoms and methamphetamine/crystal use regardless of viral load [depressive symptoms $2.96(2.37,3.71), p<0.001$ undetectable, $1.81(1.19,2.74), p=0.005$ detectable; methamphetamine/crystal use $\left[\begin{array}{lll}2.96 & (2.20,4.00), p & <0.001\end{array}\right.$ undetectable, $3.00(1.75,5.14), p \quad<0.001$ detectable], whereas psy-IPV was significantly associated with cocaine/crack [2.14(1.57, 2.93), $p<0.001]$, illicit opioid $[2.19(1.42,3.35), p<0.001]$, and marijuana use $[1.55(1.24,1.94), p<0.001]$ only in those with undetectable viral loads (Table 6).

\section{Discussion}

We found that psy-IPV was common among PLWH (ranging from 9 to $17 \%$ across studies) and associated with having a detectable viral load (VL > 400) among PLWH. We also found that psy-IPV was associated with depressive symptoms and most types of substance use, with the exception of non-binge alcohol use. In a sensitivity analysis, even after adjusting for physical and sexual IPV, we found psy-IPV was associated with lower odds of ART use and poorer adherence. These associations were not present in analyses that also adjusted for substance use and depressive symptoms, suggesting that substance use and depressive symptoms may be on the causal pathway between psy-IPV and HIV outcomes and act as mediators. This underscores the need to address these areas simultaneously in clinical settings.

Psy-IPV did not vary across most demographic groups, with the exception that younger PLWH were more likely to indicate it than their older counterparts. Notably, psyIPV was just as likely to be present in groups that are traditionally less-likely to be screened for IPV, such as men. This relative lack of demographic variance in reporting psy-IPV highlights the importance of screening all patients in HIV care for IPV, regardless of gender, race, or sexual orientation.

A major limitation of the majority of prior work is the lack of controlling for physical and sexual IPV in order to determine if psy-IPV has an independent effect on health outcomes in the absence of physical and/or sexual IPV. Prior work in the general population attempting to parse out the effects of psy-IPV from physical or sexual IPV has shown that, in a large sample of women, compared to those that had not experienced IPV of any kind, women indicating psy-IPV in the absence of physical or sexual IPV reported poorer physical and mental health as well as higher likelihood of having had a sexually transmitted infection, and higher likelihood of reporting physical symptoms [30].

Our findings also echo those of Jewkes et al. [25] which found emotional abuse to be associated with decline in cellular immunity, and Shafer et al. [24] which found psy-IPV to be associated with CD $4<200$ and detectable viral load, and 'being threatened by a partner' to be associated with these factors as well as a high noshow rate in HIV care. Our study builds on these using a larger multi-site sample, measures that were validated across sub-populations of PLWH, and the use of patient self-report to elicit data rather than the use of structured interviews, the former of which is known to reduce response bias in IPV reporting [50].

Given a) the suspected impact of psy-IPV on health outcomes even in the absence of physical or sexual IPV, b) the high prevalence of psy-IPV among PLWH compared to other types of IPV, and c) that those reporting psy-IPV in the absence of physical or sexual IPV have shown to be more at risk for continued exposure to psyIPV [29], we stress the importance of IPV screening that includes a psychological dimension. Psy-IPV remained associated with ART adherence after controlling for depressive symptoms and substance use, adding another

Table 6 Associations between psy-IPV and outcomes, stratified by detectable VL. Inverse probability of treatment weights (IPTW) used based on propensity scores

\begin{tabular}{lll}
\hline & $\begin{array}{l}\text { IPW with propensity score including age, site, race/ethnicity } \\
\text { only - Undetectable VL }\end{array}$ & $\begin{array}{l}\text { IPW with propensity score including age, site, } \\
\text { race/ethnicity only - Detectable VL }\end{array}$ \\
\hline $\begin{array}{l}\text { Characteristic } \\
\text { Depression }\end{array}$ & OR for IPV $(95 \%$ Cl),p-value & OR for IPV $(95 \%$ Cl),p-value \\
$\begin{array}{l}\text { Methamphetamine/ } \\
\text { crystal use }\end{array}$ & $2.96(2.37,3.71),<0.001$ & $1.81(1.19,2.74), 0.005$ \\
Cocaine/crack use & $2.14(1.57,2.93), 4.00),<0.001$ & $3.00(1.75,5.14),<0.001$ \\
Opioid use & $2.19(1.42,3.35),<0.001$ & $0.82(0.55,1.21), 0.3$ \\
Marijuana use & $1.55(1.24,1.94),<0.001$ & $0.83(0.50,1.37), 0.5$ \\
Alcohol use & $0.99(0.78,1.24), 0.9$ & $0.95(0.62,1.44), 0.8$ \\
Binge alcohol use & $1.15(0.92,1.43), 0.2$ & $1.43(0.95,2.16), 0.08$ \\
\hline
\end{tabular}


important dimension for understanding and addressing factors contributing to suboptimal adherence. Screening for IPV has improved provider documentation of identification of IPV and referrals [51]. In one large study, computer-based screening for IPV increased rates of IPV discussion, disclosure, and services provided in emergency clinic settings [52]; in another study, it was far more effective than usual care in identifying IPV: 19\% of women who were administered the screening indicated IPV vs. $1 \%$ among the controls $(n=1005)$ [53]. Relative to face-to-face screening, computer-based screening has been shown to be more effective in identifying IPV and to be as effective as clinician interview in terms of disclosure, patient comfort, and time spent screening [50], in addition, it has shown to be well tolerated by patients and clinicians [50], even preferred to in-person questioning [54]. Importantly, computer-based screening has not been shown to increase prevalence of IPV [54].

For these reasons, we recommend same-day, pre-visit, computer-based, patient-administered PRO screening for IPV including both physical/sexual and psy-IPV in HIV care for patients of all genders, accompanied by measures of substance use, depressive symptoms, and ART adherence, as a standard of care in HIV care settings. Further, we recommend additional research into other factors that affect PLWH that may influence susceptibility to psy-IPV. These include environmental factors, such as housing status, financial need, experience of HIV-related stigma, and social support, as well as person-level factors such as changes to cognitive function or depression. Finally, we recommend further investigation into possible mediating factors that may affect the relationship between psy-IPV and HIV-related outcomes in order to inform future interventions as well as additional research to better understand the mechanisms by which psy-IPV impacts these outcomes.

\section{Strengths}

The multi-site nature of this study yielded a demographically and geographically diverse sample of study participants.

\section{Limitations}

Study data was heavily weighted towards CNICS (87\%). Also, since data for physical and sexual IPV was not harmonizable across both consortia, we were only able to examine outcomes of psy-IPV in the context of known presence or absence of physical and sexual violence for PLWH in CNICS. The fact that participating PLWH in the study were at least somewhat engaged in care may have introduced selection bias, as those out of care may experience greater psychological abuse and more adverse health outcomes. We note that while all three study populations are care-based groups, study criteria varied, as did the IPV assessment including the platform and setting, which, while increasing generalizability, may influence interpretability of the results. Finally, due to the cross-sectional nature of the study, we were not able to determine the directionality of associations such as between substance use and psy-IPV.

\section{Conclusion}

Psychological IPV, even in the absence of physical or sexual IPV, is associated with poorer health behaviors, including higher rates of substance use, lower ART adherence, and worse virologic outcomes. Patient-reported, self-administered measures of IPV show promise in helping providers identify IPV. In outpatient HIV care, such measures should include items querying psychological violence, and be accompanied by measures of depressive symptoms, adherence, and substance use.

\section{Abbreviations}

ART: Antiretroviral therapy; ASSIST: Alcohol, Smoking and Substance Involvement Screening Test; AUDIT-C: Alcohol Use Disorders Identification Test; CNICS: Centers for AIDS Research Network of Integrated Clinical Systems; IPTW: Inverse probability treatment weight; IPV: Intimate partner violence; MSM: Men who have sex with men; PACTO: Proveyendo Acceso a Cuidado y Tratamiento; PLWH: Patients living with HIV; Psy-IPV: Psychological intimate partner violence; STTR: Seek, Test, Treat, Retain initiative

\section{Supplementary Information}

The online version contains supplementary material available at https://doi. org/10.1186/s12889-021-11854-x.

\section{Additional file 1. \\ Additional file 2 .}

\section{Acknowledgements}

The authors would like to thank the research teams associated with the Seek, Test, Treat, and Retain Data Collection and Harmonization Initiative whose collaboration has made this project possible and particularly the participants in the individual STTR studies for their valuable contributions. A full list of participating STTR investigators and institutions can be found at http://www.sttr-hiv.org. Research presented in this paper is the result of secondary data analyses associated with the STTR Data Collection and Harmonization Initiative.

\section{Authors' contributions}

Conceptualization: RF, HC, RN, JD, BW. Data curation: BW, JD, RN, BH. Formal analysis: BW, RN, JD, HC. Methodology: BW, RN, JD, HC, RF, SR, BH. Project administration: BW. Supervision: RF, JD, HC, RN. Writing-original draft: RF, RN, EF. Writing-review and editing: RF, BW, RN, HC, JD, EF, KM, CD, JE, DF, AK, WM, LM, MM, JP, CO, SN, BR. All authors have read and approved this manuscript.

\section{Funding}

This work was supported by U01DA037702 from the National Institute on Drug Abuse (NIDA). For this manuscript, we harmonized data from the following grants: Project RETAIN: 1R01DA032098-01 and Project PACTo: R01DA035280. CNICS is supported by the National Institute of Allergy and Infectious Diseases (NIAID) CNICS (R24 Al067039). Additional support from NIAID includes the University of Washington Center for AIDS Research (Grant No. P30 Al027757), and University of Alabama, Birmingham Center for AIDS Research (CFAR) (Grant No. P30 Al027767).

The views expressed in this paper are those of the authors and do not reflect those of the National Institute on Drug Abuse or the National Institutes of Health. 


\section{Availability of data and materials}

Data and materials are archived by both the University of Washington Data Coordinating Center and NIDA. They can be made available upon reasonable request, with a concept proposal and fully executed data use agreement (due to the sensitivity of the data). Interested investigators can email jacd@uw.edu for more details.

\section{Declarations}

\section{Ethics approval and consent to participate}

Human subject research approval was obtained via the each associated institution's Institutional Review Boards. For the PACTO and RETAIN studies, approval was obtained via Miami University IRB. For sites within CNICS, approval was obtained from University of Washington, University of Alabama at Birmingham, and Fenway Community Health for CNICS; for remaining CNICS sites (Case Western Reserve University, University of North CarolinaChapel Hill, University of California at San Diego), IPV measures are integrated into routine clinical care yielding de-identified data. Informed written consent was obtained by all study participants where applicable.

\section{Consent for publication}

Not applicable.

\section{Competing interests}

None.

\section{Author details}

'Department of Medicine, University of Washington, Seattle, Washington, USA. ${ }^{2}$ Department of Global Health, Emory University, Atlanta, Georgia. ${ }^{3}$ School of Global Public Health, University of North Carolina, Chapel Hill, North Carolina, USA. ${ }^{4}$ Department of Public Health Sciences, University of Miami, Miami, Florida, USA. ${ }^{5}$ Department of Medicine, Emory University, Atlanta, Georgia. ${ }^{6}$ Department of Medicine, University of California - San Diego, San Diego, California, USA. ${ }^{7}$ The Fenway Institute, Boston, MA, USA. ${ }^{8}$ Department of Sociomedical Sciences, Columbia University, New York, NY, USA. ${ }^{9}$ Department of Medicine, University of Alabama - Birmingham, Birmingham, AL, USA. ${ }^{10}$ Department of Medicine, Harvard University, Cambridge, MA, USA. ${ }^{11}$ Department of Psychiatry, Massachusetts General Hospital, Boston, MA, USA. ${ }^{12}$ Department of Epidemiology, University of North Carolina, Chapel Hill, North Carolina, USA. ${ }^{13}$ Department of Medicine, Case Western Reserve University, Cleveland, OH, USA. ${ }^{14}$ College of Pharmacy, University of Manitoba, Winnipeg, Manitoba, USA.

\section{Received: 25 August 2020 Accepted: 24 September 2021} Published online: 09 October 2021

\section{References}

1. Preventing Intimate Partner Violence: Center for Disease Control; [updated October 9, 2020. Available from: https://www.cdc.gov/violenceprevention/ intimatepartnerviolence/fastfact.html.

2. World Health Organization. Violence against women prevalence estimates, 2018. 2021.

3. Finneran C, Stephenson R. Intimate partner violence among men who have sex with men: a systematic review. Trauma Violence Abuse. 2013;14(2):16885. https://doi.org/10.1177/1524838012470034.

4. Stephenson R, Finneran C. Receipt and perpetration of intimate partner Violence and Condomless anal intercourse among gay and bisexual men in Atlanta. AIDS Behav. 2017;21(8):2253-60. https://doi.org/10.1007/s10461-01 7-1709-6.

5. National Criminal Justice Reference Service. Intimate partner violence: trends [Available from: https://www.ncjrs.gov/ovc_archives/ncvrw/2017/images/ en_artwork/Fact_Sheets/2017NCVRW_IPV_508.pdf.

6. Pantalone DW, Rood BA, Morris BW, Simoni JM. A systematic review of the frequency and correlates of partner abuse in HIV-infected women and men who partner with men. J Assoc Nurses AIDS Care. 2014;25(1 Suppl):S15-35. https://doi.org/10.1016/j.jana.2013.04.003.

7. Kalokhe AS, Paranjape A, Bell CE, Cardenas GA, Kuper T, Metsch LR, et al. Intimate partner violence among HIV-infected crack cocaine users. AIDS Patient Care STDs. 2012;26(4):234-40. https://doi.org/10.1089/apc.2011.0275.

8. Greenwood GL, Relf MV, Huang B, Pollack LM, Canchola JA, Catania JA. Battering victimization among a probability-based sample of men who have sex with men. Am J Public Health. 2002;92(12):1964-9. https://doi. org/10.2105/AJPH.92.12.1964.

9. Pantalone DW, Hessler DM, Simoni JM. Mental health pathways from interpersonal violence to health-related outcomes in HIV-positive sexual minority men. J Consult Clin Psychol. 2010;78(3):387-97. https://doi.org/10.1 037/a0019307.

10. Siemieniuk RA, Krentz HB, Miller P, Woodman K, Ko K, Gill MJ. The clinical implications of high rates of intimate partner violence against HIV-positive women. J Acquir Immune Defic Syndr. 2013;64(1):32-8. https://doi.org/10.1 097/QAl.0b013e31829bb007.

11. Siemieniuk RA, Miller P, Woodman K, Ko K, Krentz HB, Gill MJ. Prevalence, clinical associations, and impact of intimate partner violence among HIVinfected gay and bisexual men: a population-based study. HIV Med. 2013; 14(5):293-302. https://doi.org/10.1111/hiv.12005.

12. Hankin A, Smith LS, Daugherty J, Houry D. Correlation between intimate partner violence victimization and risk of substance abuse and depression among African-American women in an urban emergency department. West J Emerg Med. 2010;11(3):252-6.

13. Beydoun HA, Beydoun MA, Kaufman JS, Lo B, Zonderman AB. Intimate partner violence against adult women and its association with major depressive disorder, depressive symptoms and postpartum depression: a systematic review and meta-analysis. Soc Sci Med. 2012;75(6):959-75. https://doi.org/10.1016/j.socscimed.2012.04.025.

14. Devries KM, Mak JY, Bacchus $\amalg$, Child JC, Falder G, Petzold M, et al. Intimate partner violence and incident depressive symptoms and suicide attempts: a systematic review of longitudinal studies. PLoS Med. 2013;10(5):e1001439. https://doi.org/10.1371/journal.pmed.1001439.

15. Trevillion K, Oram S, Feder G, Howard LM. Experiences of domestic violence and mental disorders: a systematic review and meta-analysis. PLoS One. 2012;7(12):e51740. https://doi.org/10.1371/journal.pone.0051740.

16. Overstreet NM, Willie TC, Hellmuth JC, Sullivan TP. Psychological intimate partner violence and sexual risk behavior: examining the role of distinct posttraumatic stress disorder symptoms in the partner violence-sexual risk link. Womens Health Issues. 2015;25(1):73-8. https://doi.org/10.1016/j.whi.2 014.10.005.

17. Duncan DT, Goedel WC, Stults CB, Brady WJ, Brooks FA, Blakely JS, et al. A study of intimate partner violence, substance abuse, and sexual risk behaviors among gay, bisexual, and other men who have sex with men in a sample of geosocial-networking smartphone application users. Am J Mens Health. 2018:12(2):292-301.

18. Hink AB, Toschlog E, Waibel B, Bard M. Risks go beyond the violence: association between intimate partner violence, mental illness, and substance abuse among females admitted to a rural level I trauma center. J Trauma Acute Care Surg. 2015;79(5):709-14; discussion 15-6. https://doi. org/10.1097/TA.0000000000000856.

19. Beydoun HA, Williams M, Beydoun MA, Eid SM, Zonderman AB. Relationship of physical intimate partner violence with mental health diagnoses in the Nationwide emergency department sample. J Women's Health (Larchmt). 2017;26(2):141-51. https://doi.org/10.1089/jwh.2016.5840.

20. Devries KM, Child JC, Bacchus L, Mak J, Falder G, Graham K, et al. Intimate partner violence victimization and alcohol consumption in women: a systematic review and meta-analysis. Addiction. 2014;109(3):379-91. https:// doi.org/10.1111/add.12393.

21. Stall R, Mills TC, Williamson J, Hart T, Greenwood G, Paul J, et al. Association of co-occurring psychosocial health problems and increased vulnerability to HIV/AIDS among urban men who have sex with men. Am J Public Health. 2003;93(6):939-42. https://doi.org/10.2105/ajph.93.6.939.

22. Williams JK, Wilton L, Magnus M, Wang L, Wang J, Dyer TP, et al. Relation of childhood sexual abuse, intimate partner Violence, and depression to risk factors for HIV among black men who have sex with men in 6 US cities. Am J Public Health. 2015;105(12):2473-81. https://doi.org/10.2105/AJPH.2015.302878.

23. Kalokhe AS, Ibegbu CC, Kaur SP, Amara RR, Kelley ME, Del Rio C, et al. Intimate partner violence is associated with increased Cd4+ T-cell activation among Hiv-negative high-risk women. Pathog Immun. 2016;1 (1):193-213. https://doi.org/10.20411/pai.v1i1.120.

24. Schafer KR, Brant J, Gupta S, Thorpe J, Winstead-Derlega C, Pinkerton R, et al. Intimate partner violence: a predictor of worse HIV outcomes and engagement in care. AIDS Patient Care STDs. 2012;26(6):356-65. https://doi. org/10.1089/apc.2011.0409.

25. Jewkes R, Dunkle K, Jama-Shai N, Gray G. Impact of exposure to intimate partner violence on CD4+ and CD8+ T cell decay in HIV infected women: 
longitudinal study. PLoS One. 2015;10(3):e0122001. https://doi.org/10.1371/ journal.pone.0122001.

26. Ali B, Mittal M, Schroder A, Ishman N, Quinton S, Boekeloo B. Psychological violence and sexual risk behavior among predominantly African American women. J Interpers Violence. 2017;886260517720734(23-24):5574-88. https:// doi.org/10.1177/0886260517720734.

27. Lovestad S, Love J, Vaez M, Krantz G. Prevalence of intimate partner violence and its association with symptoms of depression; a cross-sectional study based on a female population sample in Sweden. BMC Public Health. 2017;17(1):335. https://doi.org/10.1186/s12889-017-4222-y.

28. Thompson RS, Bonomi AE, Anderson M, Reid RJ, Dimer JA, Carrell D, et al. Intimate partner violence: prevalence, types, and chronicity in adult women. Am J Prev Med. 2006;30(6):447-57. https://doi.org/10.1016/j.amepre.2006.01. 016.

29. Blasco-Ros C, Sanchez-Lorente S, Martinez M. Recovery from depressive symptoms, state anxiety and post-traumatic stress disorder in women exposed to physical and psychological, but not to psychological intimate partner violence alone: a longitudinal study. BMC Psychiatry. 2010;10(1):98. https://doi.org/10.1186/1471-244X-10-98.

30. Coker AL, Smith PH, Bethea L, King MR, McKeown RE. Physical health consequences of physical and psychological intimate partner violence. Arch Fam Med. 2000;9(5):451-7. https://doi.org/10.1001/archfami.9.5.451.

31. Flanagan JC, Jaquier V, Overstreet N, Swan SC, Sullivan TP. The mediating role of avoidance coping between intimate partner violence (IPV) victimization, mental health, and substance abuse among women experiencing bidirectional IPV. Psychiatry Res. 2014;220(1-2):391-6. https:// doi.org/10.1016/j.psychres.2014.07.065

32. Davis A, Kaighobadi F, Stephenson R, Rael C, Sandfort T. Associations between alcohol use and intimate partner Violence among men who have sex with men. LGBT Health. 2016;3(6):400-6. https://doi.org/10.1089/lgbt.201 6.0057 .

33. Meyer JP, Springer SA, Altice FL. Substance abuse, violence, and HIV in women: a literature review of the syndemic. J Women's Health (Larchmt). 2011;20(7):991-1006. https://doi.org/10.1089/jwh.2010.2328.

34. Centers for AIDS Research Network of Integrated Clinical Systems. 2021 [Available from: https://www.uab.edu/cnics/.

35. Chandler RK, Kahana SY, Fletcher B, Jones D, Finger MS, Aklin WM, et al. Data collection and harmonization in HIV research: the seek, test, treat, and retain initiative at the National Institute on Drug Abuse. Am J Public Health. 2015;105(12):2416-22. https://doi.org/10.2105/AJPH.2015.302788.

36. Chandler R, Gordon MS, Kruszka B, Strand LN, Altice FL, Beckwith CG, et al. Cohort profile: seek, test, treat and retain United States criminal justice cohort. Subst Abuse Treat Prev Policy. 2017;12(1):24. https://doi.org/10.1186/ s13011-017-0107-4.

37. PACTo: Proveyendo Acceso a Cuidado y Tratamiento: University of Puerto Rico; 2020 [Available from: https://md.rcm.upr.edu/actu5401/proyecto-pa cto/.

38. Project RETAIN: providing integrated care for HIV-infected crack cocaine users: Cochrane Central Register of Controlled Trials; 2018 [Available from: https://www.cochranelibrary.com/es/central/doi/10.1002/central/CN-01503 866/full.

39. Kitahata MM, Rodriguez BG, Haubrich R, Boswell S, Mathews WC, Lederman MM, et al. Cohort profile: the centers for AIDS research (CFAR) network of integrated clinical systems (CNICS). Int J Epidemiol. 2008;37(5):948-55. https://doi.org/10.1093/ije/dym231.

40. Fitzsimmons EL, S. Dougherty, S. Mathews WC. Mugavero MJ. Mayer KH. Potter J. O'Cleirigh C. Crane PK. Crane HM. Fredericksen RJ Development and content validation of a brief patient-reported measure of intimate partner violence for use in HIV care. International Society for Quality of Life Research Annual Conference; October 2019; San Diego, CA.

41. Paranjape A, Liebschutz J. STaT: a three-question screen for intimate partner violence. J Women's Health (Larchmt). 2003;12(3):233-9. https://doi.org/10.1 089/154099903321667573.

42. Spitzer RL, Kroenke K, Williams JB. Validation and utility of a self-report version of PRIME-MD: the PHQ primary care study. Primary care evaluation of mental disorders. Patient health questionnaire. Jama. 1999;282(18):173744. https://doi.org/10.1001/jama.282.18.1737.

43. Kroenke K, Spitzer RL, Williams JB. The PHQ-9: validity of a brief depression severity measure. J Gen Intern Med. 2001;16(9):606-13. https://doi.org/10.1 046/j.1525-1497.2001.016009606.x.
44. Radloff LS. The CES-D scale: a self report depression scale for resaerch in the general population. Appl Psychol Meas. 1977;1(3):385-401. https://doi.org/1 $0.1177 / 014662167700100306$

45. Lu M, Safren SA, Skolnik PR, Rogers WH, Coady W, Hardy H, et al. Optimal recall period and response task for self-reported HIV medication adherence. AIDS Behav. 2008;12(1):86-94. https://doi.org/10.1007/s10461-007-9261-4.

46. Bush K, Kivlahan DR, McDonell MB, Fihn SD, Bradley KA. The AUDIT alcohol consumption questions (AUDIT-C): an effective brief screening test for problem drinking. Ambulatory care quality improvement Project (ACQUIP). Alcohol use disorders identification test. Arch Intern Med. 1998;158(16): 1789-95. https://doi.org/10.1001/archinte.158.16.1789.

47. WHO ASSIST Working Group. The alcohol, smoking and substance involvement screening test (ASSIST): development, reliability and feasibility. Addiction. 2002;97(9):1183-94. https://doi.org/10.1046/j.1360-0443.2002.001 85.x.

48. Cepeda MS, Boston R, Farrar JT, Strom BL. Comparison of logistic regression versus propensity score when the number of events is low and there are multiple confounders. Am J Epidemiol. 2003;158(3):280-7. https://doi.org/1 0.1093/aje/kwg115.

49. Hernan MA, Brumback B, Robins JM. Marginal structural models to estimate the causal effect of zidovudine on the survival of HIV-positive men. Epidemiology. 2000;11(5):561-70. https://doi.org/10.1097/00001648-2 00009000-00012.

50. Chen P-H, Rovi S, Washington J, Jacobs A, Vega M, Pan K-Y, et al. Randomized comparison of 3 methods to screen for domestic violence in family practice. Ann Fam Med. 2007;5(5):430-5. https://doi.org/10.1370/afm. 716.

51. O'Campo P, Kirst M, Tsamis C, Chambers C, Ahmad F. Implementing successful intimate partner violence screening programs in health care settings: evidence generated from a realist-informed systematic review. Soc Sci Med. 1982;72(6):855-66. https://doi.org/10.1016/j.socscimed.2010.12.019.

52. Rhodes KV, Drum M, Anliker E, Frankel RM, Howes DS, Levinson W. Lowering the threshold for discussions of domestic violence: a randomized controlled trial of computer screening. Arch Intern Med. 2006;166(10):110714. https://doi.org/10.1001/archinte.166.10.1107.

53. Trautman DE, McCarthy ML, Miller N, Campbell JC, Kelen GD. Intimate partner violence and emergency department screening: computerized screening versus usual care. Ann Emerg Med. 2007;49(4):526-34. https://doi. org/10.1016/j.annemergmed.2006.11.022.

54. MacMillan HL, Wathen CN, Jamieson E, Boyle M, McNutt L-A, Worster A, et al. Approaches to screening for intimate partner violence in health care settings: a randomized trial. JAMA. 2006;296(5):530-6. https://doi.org/10.1 001/jama.296.5.530.

\section{Publisher's Note}

Springer Nature remains neutral with regard to jurisdictional claims in published maps and institutional affiliations.

Ready to submit your research? Choose BMC and benefit from:

- fast, convenient online submission

- thorough peer review by experienced researchers in your field

- rapid publication on acceptance

- support for research data, including large and complex data types

- gold Open Access which fosters wider collaboration and increased citations

- maximum visibility for your research: over $100 \mathrm{M}$ website views per year

At BMC, research is always in progress.

Learn more biomedcentral.com/submissions 